\title{
Influence of length of interval between pulses in PDR brachytherapy (PDRBT) on value of Biologically Equivalent Dose (BED) in healthy tissues
}

\author{
Janusz Skowronek, MD, PhD, Ass. Prof.', Julian Malicki, MSc, PhD, Prof², \\ Grzegorz Zwierzchowski, MSc, PhD², Tomasz Piotrowski, MSc, PhD² \\ IBrachytherapy Department, 2Medical Physics Department, Greater Poland Cancer Centre, Poznan', Poland
}

\begin{abstract}
Purpose: Different PDR treatment schemas are used in clinical practice, however optimal length of interval between pulses still remains unclear. The aim of this work was to compare value of BED doses measured in surrounded healthy tissues according to different intervals between pulses in PDRBT. Influence of doses optimization on BED values was analyzed.

Material and methods: Fifty-one patients treated in Greater Poland Cancer Centre were qualified for calculations. Calculations of doses were made in 51 patients with head and neck cancer, brain tumor, breast cancer, sarcoma, penis cancer and rectal cancer. Doses were calculated with the use of PLATO planning system in chosen critical points in surrounded healthy tissues. For all treatment plans the doses were compared using Biologically Equivalent Dose formula. Three interval lengths (1, 2 and 4 hours) between pulses were chosen for calculations. For statistical analysis Friedman ANOVA test and Kendall ratio were used.

Results: The median value of BED in chosen critical points in healthy tissues was statistically related to the length of interval between PDR pulses and decreased exponentially with 1 hour interval to 4 hours (Kendall = from 0.48 to 1.0; $p=$ from 0.002 to 0.00001 ).

Conclusions: Prolongation of intervals between pulses in PDR brachytherapy was connected with lower values of BED doses in healthy tissues. It seems that longer intervals between pulses reduced the risk of late complications, but also decreased the tumour control. Furthermore, optimization influenced the increase of doses in healthy tissues.
\end{abstract}

J Contemp Brachyther 2010; 2, 2:64-70 DOI: 10.5114/jcb.2010.14404

Key words: BED, PDR brachytherapy, interval between pulses, optimization.

\section{Introduction}

Brachytherapy with modern afterloading equipment offers three major advantages over interstitial and intracavitary insertions of separate needles, tubes, seeds or wires: 1. Isodose volumes in tissues can be created flexibly by a combination of careful placement of the catheter and adequate adjustment of the dwell times of the computerized stepping source. This process is usually called "dose optimization". 2. Automatic removal of radiation sources into a shielded safe whenever somebody enters the room, eliminates radiation exposure to the staff and visitors. 3. Radiation exposure to the staff is also eliminated where multiplicity of radioactive sources were formerly loaded and unloaded into the catheters, ovoids, tubes etc. [1-4].

Pulsed Dose Rate brachytherapy (PDRBT) is a new treatment that combines physical advantages of HDRBT technology (isodose optimization, planning flexibility and radiation safety) with radiobiological advantages of LDRBT brachytherapy (repair advantages) [5-8]. The single radioactive stepping source moves through all implanted catheters during each pulse. The resulting isodoses can be optimized by modulating the dwell-time of the source as a function of its trajectory within the implanted volume [6, 9-11].

In PDR brachytherapy each pulse delivers small doses followed by an interval which allows some repair and small increase of radiobiological effect. However, the main question is whether or not the increased effect is greater on late-responding normal tissues than on tumor cell kill. The interval between the pulses permits greater comfort of the patient and increased safety of the nursing staff. In principle, every removal from continuous exposure 
towards treatment with intervals carries a radiobiological disadvantage. This corresponds to fractionation with larger dose per fraction and theoretical and experimental evidence that leads to a relative increase in late normal-tissue reactions. The magnitude of this effect has been considered acceptable by Brenner and Hall who concluded that for intervals between pulses of up to 60 minutes the radiobiological deficit may be acceptable [12]. Nevertheless, the optimal length of interval between pulses remains unclear. To reproduce the biological effects of LDRBT using PDR remote afterloading Brenner and Hall [12] along with Fowler and Mount [13] have given the following four recommendations: 1 ) the same total dose, 2) the same dose rate: generally about $0.5 \mathrm{~Gy} /$ hour, 3) pulse length of 10 minutes or more (or dose rate not exceeding $3 \mathrm{~Gy} /$ hour during the pulse), 4) pulse repeated every hour, typically 0.4-1.0 Gy/hour. If these conditions are met, the biological effects of PDR brachytherapy should be equivalent to those of LDR brachytherapy for all tissues.

These conclusions were made on the basis of calculations of cell repair capacity (estimated by $\alpha / \beta$ value) and the kinetics of repair (estimated by $\mathrm{T}_{1 / 2}$ ), for both tumors and late-reacting normal tissues. The value of $\alpha / \beta$ for tumours and late reacted human tissues was estimated and is often consistent with a laboratory results using experimental animals. In contrast, caused by lack of clinical data, $\mathrm{T}_{1 / 2}$ has been estimated mainly from experimental data [14]. However, it is likely that early-responding tissues such as tumors - are repairing sublethal damage more rapidly than late-responding tissues [15-18]. In 1996, Brenner and Hall exploited this difference in order to design new therapeutic regimens. Using $\mathrm{T}_{1 / 2}$ of 0.5 hours for early-responding tissues and 4 hours for late-responding, they estimated that PDR brachytherapy delivering series of pulses separated by 3-4 hours should generate better results than LDR brachytherapy [19-21].

The aim of this work was to compare BED doses calculated in surrounded healthy tissues according to different intervals between pulses in PDR brachytherapy. We have chosen BED formula for doses calculations [22]. The influence of doses optimization on BED values was analyzed.

\section{Material and methods}

\section{Material}

Original data of 51 patients treated with PDR brachytherapy (PDRBT) in Greater Poland Cancer Centre were included into the study. Values of doses and remaining physical and biological data were analyzed in patients with different cancers presented in Table 1. The PDR radical treatment included 2 fractions of 20 Gy with 3-4 days intervals (pulses of 0.6-1 Gy hourly). In palliative PDR brachytherapy one fraction of 20 Gy was used (pulses of 0.6-0.8 Gy hourly). The lengths of pulses differed due to pulse dose value, tumour volume and number of applicators used in treatment, also depended on Ir-192 source activity. We used applicators: interstitial, elastic ("blind-end") in breast cancer, head and neck cancer, sarcomas, rectal cancer, and penis cancer, French 6 endoluminal applicators in 2 patients with nasopharyngeal cancer and steel needles in 2 patients with lip cancer. Clinical data of patients are presented in Table 1.
PDRBT was applied in compliance with European recommendations $[1,2]$, using therapeutic line (Nucletron $^{\circledR}$ ): IBU (Integrated Brachytherapy Unit), PLATO planning system and microselectron PDR.

\section{Methods}

The doses were calculated using PLATO planning system in prescribed reference point (CTV) and in surrounded healthy tissues. For doses measurements in healthy critical tissues in each group of patients critical points were chosen. They are characterized in Table 2.

In all cases, on the basis of PDRBT treatment plans, the influence of optimization on distance and volume of doses in organs at risk was examined. Organs at risk were chosen from the point of the increased risk of the late radiation complications. The model of the biological equivalent dose (BED) was used to calculate BED dose and to compare PDRBT doses. One of the BED formula advantages is its relative facility to use it in different fractionation schemas $[6,23,24]$. On the basis of literature data, the constant values of $\alpha / \beta$ ratio and $T_{1 / 2}$ ratio were chosen $[6,25,26]$. One assumed the same BED value in reference point (in the treatment area) for different PDR interval lengths. On the basis of biological equivalent, doses in critical points were calculated. Differences among biologically corresponding doses in PDR brachytherapy in critical points before and after optimization on distance and volume were analyzed.

Table 1. Patients characteristic

\begin{tabular}{|c|c|}
\hline Clinical data & Number, rate \\
\hline $\begin{array}{l}\text { Age: } \\
\text { median } \\
\text { range }\end{array}$ & $\begin{array}{c}53 \text { years } \\
22-85 \text { years }\end{array}$ \\
\hline $\begin{array}{l}\text { Gender: } \\
\text { male } \\
\text { female }\end{array}$ & $\begin{array}{l}22(43.1 \%) \\
29(56.9 \%)\end{array}$ \\
\hline $\begin{array}{l}\text { Tumor Site: } \\
\text { head and the neck cancer } \\
\text { brain tumor } \\
\text { breast cancer } \\
\text { soft tissues sarcoma } \\
\text { penis cancer } \\
\text { rectal cancer }\end{array}$ & $\begin{array}{c}15 \\
23 \\
8 \\
3 \\
1 \\
1\end{array}$ \\
\hline $\begin{array}{l}\text { Methods of treatment: } \\
\text { head and the neck cancer } \\
\text { brain tumor } \\
\text { breast cancer } \\
\text { soft tissues sarcoma } \\
\text { penis cancer } \\
\text { rectal cancer }\end{array}$ & $\begin{array}{l}\text { radical }-2 \\
\text { palliative }-13 \\
\text { palliative }-23 \\
\text { radical }-8 \\
\text { radical }-2 \\
\text { palliative }-1 \\
\text { palliative }-1 \\
\text { palliative }-1\end{array}$ \\
\hline Doses & \\
\hline $\begin{array}{l}1 \times 10 \text { Gy (breast cancer) } \\
1 \times 20 \text { Gy (palliative treatment) } \\
2 \times 20 \text { Gy (radical treatment) }\end{array}$ & $\begin{array}{c}8 \\
39 \\
4\end{array}$ \\
\hline
\end{tabular}


The comparison of biological effect of total doses were made by using the linear-quadratic formula and monoexponential repair models [25-27]. One assumed that radiation induced injuries during interval between brachytherapy fractions could be incompletely repaired, especially if $\mathrm{T}_{1 / 2}$ is relatively high in relation to length of this period. This incomplete repair increases BED and requires adequate correction in calculations. The irradiation is delivered over a period of time comparable to low dose rate brachytherapy, however it is not continuous. The dose is delivered in pulses that are repeated in intervals of 1-4 hours. This interval between fractions is not sufficient enough to allow complete repair of sublethal damage. The estimation of equivalent dose takes into account incomplete repair factor (" $\left.\mathrm{H}_{\mathrm{m}}{ }^{\prime}\right)$, which depends on the number of fractions per day, the interval between fractions, and $\mathrm{T}_{1 / 2}$ [1].

For all treatment plans and all critical points the doses were compared using BED (Biologically Equivalent Dose) formula with three interval lengths of 1.2 and 4 hours. This formula was presented earlier by Thames and Hendry [28], justified by Steel [22]:

$$
\operatorname{BED}=\mathrm{D}\left[1+\mathrm{d} /(\alpha / \beta)+\mathrm{H}_{\mathrm{m}} \times \mathrm{d} /(\alpha / \beta)\right],
$$

where:

$\Phi=\exp (-\mu \Delta \mathrm{T})$

$H_{m}=2 / \mathrm{m} \times[\Phi /(1-\Phi)] \times\left[\mathrm{m}-\left(\left(1-\Phi^{\mathrm{m}}\right) /(1-\Phi)\right)\right]$

$D$ - total dose, $d$ - fraction dose, $m$ - number of daily

fractions, $\Delta T-$ interval between fractions (pulses).
We choose values of $\alpha / \beta$ : 1) for tumors, early reactions tissues $\alpha / \beta=10 \mathrm{~Gy}, 2)$ for late reaction tissues $\alpha / \beta=3 \mathrm{~Gy}$, values of $T_{1 / 2}: 0.5 \mathrm{~h}$ for tumors, early reactions tissues and $\mathrm{T}_{1 / 2}=1.5 \mathrm{~h}$ for late reaction tissues. Value $\mu$ is constant: $\log _{e} 2 / \mathrm{T}_{1 / 2}=0.693 / \mathrm{T}_{1 / 2}$. Then for $\mathrm{T}_{1 / 2}=0.5 \mathrm{~h} \mu$ carry out 1.386 , and for $T_{1 / 2}=1.5 \mathrm{~h}-0.462$, respectively. In every case of a treatment plan the contained doses distribution in reference point and in critical points were calculated for following dwell-times. Dose distribution were calculated using real treatment plans of all 51 patients treated with PDRBT. Optimization on distance was done for applications where the catheters lied in a single plane (slab volume) and where an isodose surface was required at a given distance from the catheters. Optimization on volume was done for applications where the catheters lied in multiple planes, aiming at a homogeneous dose distribution inside the PTV, i.e. and minimized the spread of the local doses. Only dwell positions that lied in catheters other than the catheter for which the dwell limes were calculated, were taken into consideration [1].

For statistical analysis Friedman ANOVA test and Kendall ratio were used.

\section{Results}

Analysis of doses values in PDR brachytherapy indicates the undesirable increase of the dose (from 1.9 to 13.4 Gy) in most of the points in organs at risk after the optimization. It shows the probability of undesirable increase of the risk of late complications in these healthy

Table 2. Critical points in healthy tissues chosen for calculations

\begin{tabular}{|c|c|c|}
\hline Tumor & Critical point & Description \\
\hline Head and the neck cancer & $\begin{array}{l}\text { 1) external jaw surface } \\
\text { 2) internal jaw surface } \\
\text { 3) external ear } \\
\text { 4) spinal cord } \\
\text { 5) orbit } \\
\text { 6) brain }\end{array}$ & $\begin{array}{l}1 \text { and } 2 \text { - points located in central plane } \\
\text { of applicator } \\
4 \text { - point located in the middle of applicator } \\
5 \text { - point located in nearest distance from applicator } \\
6 \text { - point located on base of the skull, lying in } \\
\text { nearest distance from applicator }\end{array}$ \\
\hline Brain tumor & $\begin{array}{l}\text { 1) orbit } \\
\text { 2) sella } \\
\text { 3) chiazma opticum } \\
\text { 4) external ear } \\
\text { 5) epipharynx }\end{array}$ & points located in nearest distance from applicator \\
\hline Breast cancer & $\begin{array}{l}\text { 1) three points on external surface of pleura } \\
\text { 2) three points on skin }\end{array}$ & $\begin{array}{l}1 \text { and } 2 \text { - points located every } 2 \mathrm{~cm} \text {, center point } \\
\text { located on medial level of applicator }\end{array}$ \\
\hline Soft tissues sarcoma & $\begin{array}{l}\text { 1) three points on bone surface } \\
\text { 2) three points on skin }\end{array}$ & $\begin{array}{l}1 \text { and } 2 \text { - points located every } 2 \mathrm{~cm} \text {, center point } \\
\text { located on medial level of applicator }\end{array}$ \\
\hline Penis cancer & $\begin{array}{l}\text { 1) pubic symphysis } \\
\text { 2) epidydimis } \\
\text { 3) ischiadic tuber } \\
\text { 4-6) three points on skin surface }\end{array}$ & points located in nearest distance from applicator \\
\hline Rectal cancer & $\begin{array}{l}\text { 1) femoral bone head } \\
\text { 2) sacra bone } \\
\text { 3) pubic symphysis } \\
\text { 4) obturator foramen } \\
\text { 5) urinary bladder } \\
\text { 6) mons pubis }\end{array}$ & points located in nearest distance from applicator \\
\hline
\end{tabular}


organs after standard use of optimization. The median value of BED in chosen critical points in healthy tissues was statistically related to the length of interval between PDR pulses and reduced exponentially with the increase from 1 hour interval to 4 hours (Kendall = from 0.48 to 1.0, $p=$ from 0.002 to 0.00001 ). The optimization has influenced the increase of doses in all measured points in healthy tissues. Summarized BED values with different interval length and optimization status are presented in Table 3.

\section{Comparison of BED values for different interval length - before optimization}

Median BED value in each critical point was statistically significant and was depending from interval length, declined exponentially with interval growth - from 1 , to 2 and 4 hours (Kendall ratio $=$ from 0.48 to $1.0, p=$ from 0.002 to 0.00001 ). Exemplary BED values for critical point "external jaw surface" carried out: 1 h - 24.4 Gy, 2 h - 18.3 Gy, 4 h - 15.6 Gy, for critical point "internal jaw surface": 1 h - 27.6 Gy, $2 \mathrm{~h}-20.4 \mathrm{~Gy}, 4 \mathrm{~h}-17.1 \mathrm{~Gy}$, for point "sella": $1 \mathrm{~h}-21.9 \mathrm{~Gy}$, $2 \mathrm{~h}-16.1 \mathrm{~Gy}, 4 \mathrm{~h}-13.5 \mathrm{~Gy}$. Results testify that with the growth of interval length, the BED value decreases in healthy tissues. Comparison of BED values [cGy] PDRBT (1-h interval) and PDRBT (2-h, 4-h interval) in whole group of patients for all critical points before optimization presents Fig. 1.

\section{Comparison of BED values for different interval length - after optimization on distance}

Median BED value in each critical point was statistically significant and was depending from interval length, declined exponentially with interval growth - from 1, to 2 and 4 hours (Kendall ratio $=$ from 0.43 to $1.0, p=$ from 0.0002 to 0.00001 ). Exemplary BED values for critical point "external jaw surface" carried out: 1 h - 25.4 Gy, 2 h 19.1 Gy, 4 h - 16.3 Gy, for critical point "internal jaw surface": 1 h - 25.2 Gy, 2 h - 19 Gy, 4 h - 16.2 Gy, for point "sella": 1 h - 36 Gy, 2 h - 24.9 Gy, 4 h - 19.8 Gy.

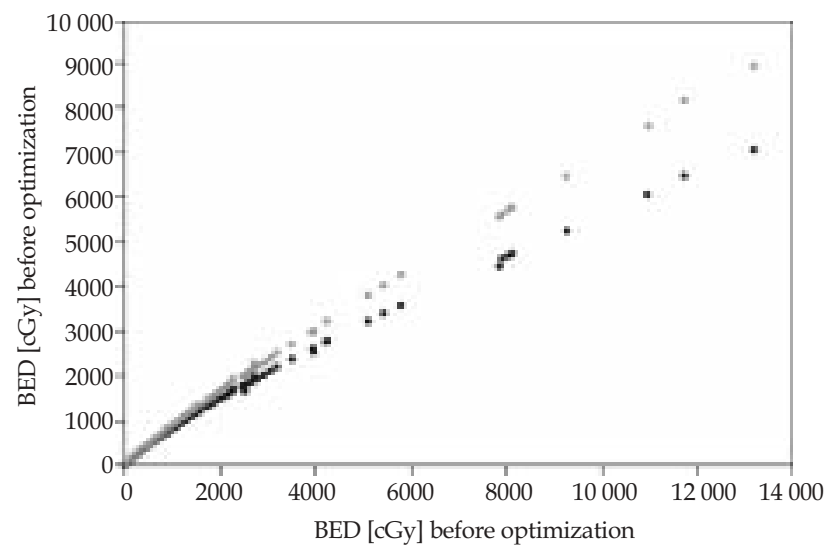

- $\operatorname{PDR}(1-\mathrm{h})$ vs. PDR (4-h)

* PDR (1-h) vs. PDR (2-h)

Fig. 1. Comparison of BED PDR (1-h interval) with BED PDR (2- and 4-h interval) of all patients (before optimization)
Table 3. Summarized BED values - different interval length and optimization status

\begin{tabular}{lccc}
\multicolumn{2}{c}{ Options of PDR treatment } & \multicolumn{2}{c}{ BED } \\
\hline $\begin{array}{l}\text { Optimalization } \\
\text { method }\end{array}$ & $\begin{array}{c}\text { Time between } \\
\text { pulse }[\mathrm{h}]\end{array}$ & $\begin{array}{c}\text { Mean } \\
{[\mathrm{Gy}]}\end{array}$ & $\begin{array}{c}\text { SD } \\
{[\mathrm{Gy}]}\end{array}$ \\
\hline No & 1 & 24.4 & 29.9 \\
\cline { 2 - 4 } & 2 & 18.3 & 20.8 \\
\cline { 2 - 4 } & 4 & 15.6 & 16.8 \\
\hline Point & 1 & 25.4 & 29.2 \\
\cline { 2 - 4 } & 2 & 19.1 & 20.4 \\
\hline Volume & 4 & 16.2 & 16.5 \\
\cline { 2 - 4 } & 1 & 10.6 & 7.4 \\
\cline { 2 - 4 } & 2 & 9.0 & 5.8 \\
\hline
\end{tabular}

Similar dependences were observed in calculations of BED doses before the optimization and after volume optimization. Comparison of BED values [cGy] PDRBT (1-h interval) and PDRBT (2-h, 4-h interval) in whole group of patients for all critical points after optimization on distance presents Fig. 2.

\section{Comparison of BED values for different interval length - after optimization on volume}

Median BED value in each critical point was statistically significant and was depending from interval length, declined exponentially with interval growth - from 1, to 2 and 4 hours (Kendall ratio $=$ from 0.44 to $1.0, p=$ from 0.001 to 0.00001 ). Similar dependences were observed like in calculations for BED doses before optimization and after optimization on distance. Comparison of BED values [cGy] PDRBT (1-h interwal) and PDRBT (2-h, 4-h interval) in whole group of patient for all critical points after optimization on volume is presented in Fig. 3.

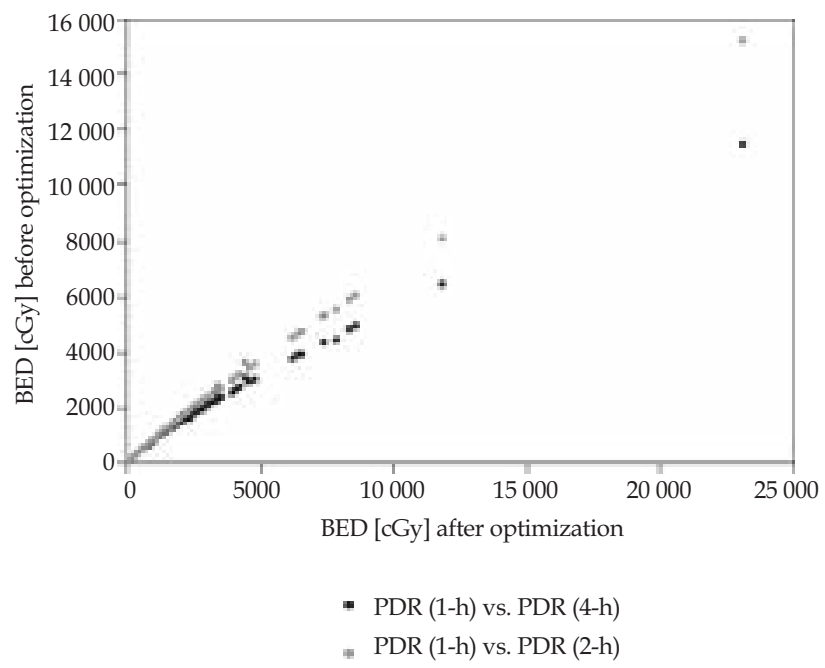

Fig. 2. Comparison of BED PDR (1-h interval) with BED PDR (2- and 4-h interval) of all patients (data after optimization on distance) 


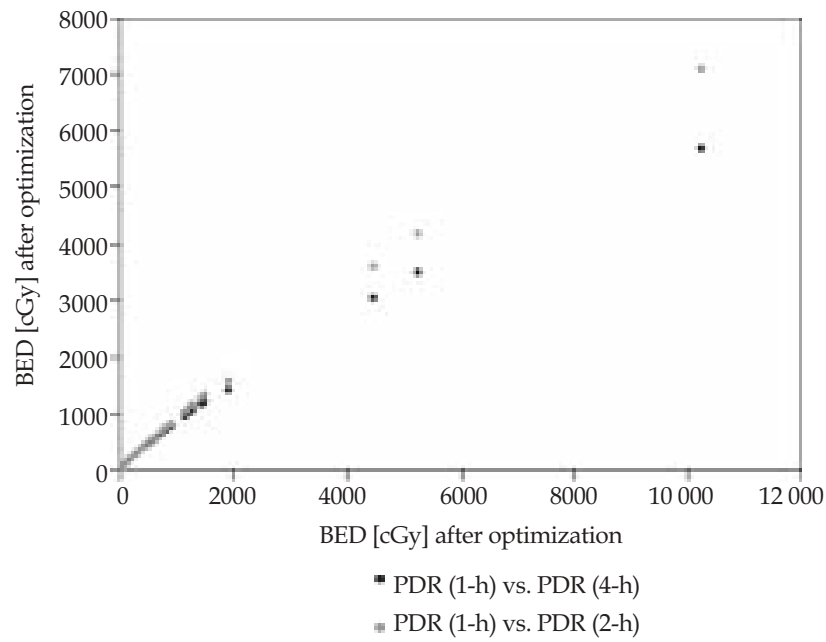

Fig. 3. Comparison of BED PDR (1-h interval) with BED PDR (2- and 4-h interval) of all patients (data after optimization on volume)

BED values in exemplary critical point "internal jaw surface" are presented in Fig. 4. Prolongation of interval length was connected with BED value decrease.

\section{Discussion}

Modern computer planning systems permits much better possibilities in achieving requested dose levels at specified points or volumes of clinical interest (such as organs at risk) than manual methods. In general, such a match is attained by optimizing the source configuration (positions and/or strengths). The adjustment of the source configuration may be performed intuitively by a planner or automatically by computer. The computer with the use of algorithms incorporates a set of decision criteria that resembles the criteria used by the physician [1]. Ideally there should be zero dose outside the treated tumor (PTV) i.e. and no dose deposited to critical structures, which in our work is called as critical points. For normal tissue damage there is a strong correlation between dose, volume and the occurrence of certain end-points. We observed that an addition to the optimization influenced the increase of doses in healthy tissues that were independent on the length of the interval between pulses.

Although the PDR approach has been the subject of numerous theoretical papers, and afterloading machines modified for PDR treatments have been commercially available for several years now, very little data has been published regarding clinical experience with these techniques $[7,29,30]$. Theoretical calculations indicate that pulsed dose rate irradiation should be approximately as effective as continuous low dose rate with the same total dose given in unchanged overall time $[1,14]$. In case of small doses per pulse $(<0.5 \mathrm{~Gy})$ with repair times larger than $10 \mathrm{~min}$, the differential effect to continuous LDRBT is less than $10 \%$. This is, however, not the case if large doses per pulse (> $2 \mathrm{~Gy}$ ) are used and/or there is a non-exponential or very short $\mathrm{T}_{1 / 2}(<0.5 \mathrm{~h})$ [31-35].

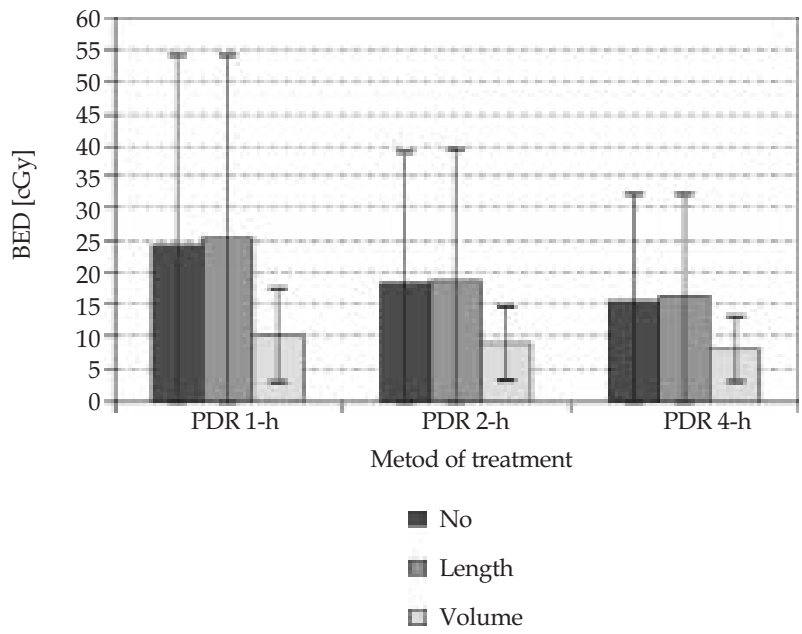

Fig. 4. BED values in exemplary critical point "internal jaw surface" - before and after optimization on distance and volume

Experimental data are available from a variety of animal experiments [1]. In a mouse jejunum, Mason et al. [36] found continuous LDRBT at $0.7 \mathrm{~Gy} / \mathrm{h}$ and PDR with 0.7 Gy hourly pulses to be of equal effectiveness. Pulse duration was around $10 \mathrm{~min}$. Shortening the pulse down to 1 min marginally increased the effectiveness by 3-4\%. This is caused by fast repair kinetics of the jejunum. Armour et al. [37] investigated different PDR schedules in a rat rectum, where the endpoint resulted as a late rectal stenosis. The reference LDR protocol used dose rate of $0.75 \mathrm{~Gy} / \mathrm{h}$. The PDR schedules were similarly effective when pulses of $0.375,0.75$ and $1.5 \mathrm{~Gy}$ were given at $30 \mathrm{~min}$, $1 \mathrm{~h}$ or $2 \mathrm{~h}$ intervals, respectively. Larger pulses of $3 \mathrm{~Gy}$ every $4 \mathrm{~h}$ resulted in 15\% increase in efficiency and pulses of 6 Gy every $8 \mathrm{~h}$ resulted in $30 \%$ increase in effectiveness. This reference dose rate of $0.75 \mathrm{~Gy} / \mathrm{h}$ is high. In a clinic it would correspond to 3 days and $8 \mathrm{~h}$ treatment with a total dose of $60 \mathrm{~Gy}$, i.e. Lower reference dose rate of 0.4-0.5 Gy/h would have been more clinically relevant, although probably not relatively feasible with this model [1]. Brenner et al. [20] have compared LDR and PDR schedules in a rat cataract model. A dose of 15 Gy was delivered to a rat eye: 1$)$ continuously over $24 \mathrm{~h}(0.625 \mathrm{~Gy} / \mathrm{h})$ or 2 ) with hourly pulses of $10 \mathrm{~min}, 3)$ with $10 \mathrm{~min}$ pulses every $4 \mathrm{~h}$, and 4 ) with hourly pulses of about $1 \mathrm{~min}$. All schedules were found to be isoeffective. Haustermans et al. [38] attempted to define a pulsed dose rate of isoeffective protocol with a continuous low dose rate irradiation of a rat cervical spinal cord. Two different schedules were used, delivering pulses of 0.69 Gy at $1 \mathrm{~h}$ repetition (9 pulses/day) and of 2 Gy at 3 h repetition (4 pulses/day), with overnight intervals of 12-15 h. The reference LDR exposure used a range of dose rates up to $0.94 \mathrm{~Gy} / \mathrm{h}$. Pulsed dose rate irradiation was more effective than low dose rate by a factor of 10 to $17 \%$. The most probable explanation was that was a substantial component of repair with very short $\mathrm{T}_{1 / 2}$ in the spinal cord. Multi-exponential repair has been shown to offer a better fitting to spinal cord repair 
in more recent experiments [39]. These data emphasize some inadequacies of using mono-exponential repair models as an approximation to multi-exponential repair, which is particularly critical in pulsed dose rate isoeffect calculations. Data on normal tissue repair in humans are unfortunately extremely limited [1]. The radiobiological modeling of pulsed dose rate is difficult, due to numerous uncertainties regarding DNA repair parameters [40-43]. Theoretical pulsed dose rate protocols, which could simulate a continuous low dose rate treatment, have been worked out [12, 13, 20, 33, 34, 36, 44]. Several of the conclusions were rather similar regarding the necessity to deliver pulses of at least 10 minutes per hour using a source with the lowest possible activity. It must be emphasized once more that these calculations are based on a hypothesis concerning the half time repair for early and late responding normal tissues as well as tumors [13, $33,34]$. As stated previously, the available data on the kinetics of DNA repair are quite insufficient [1].

An important, yet often forgotten element in theoretical calculations of isoeffects is the reference low dose rate used in the model. Conventional low dose rate in Paris or Manchester system delivers 10 to 12 Gy per day (0.4-0.5 Gy/h). Higher dose intensity, for instance 15 or 17 Gy/day, has much greater biological effectiveness [45]. Therefore, the reference low dose rate is very critical for isoeffect calculations, as critical as the $\alpha / \beta$ and $T_{1 / 2}$ values [1]. In addition to its limitations as a biological model, the linear-quadratic isoeffect model does not account for the peculiar, stepwise accumulation of absorbed dose throughout the target volume with current PDR afterloading equipment. In order to build up, over 10 minutes, a dose distribution that mimics linear sources, the point source needs to cover a large number of consecutive steps, each one being only briefly, but intensely exposed. Therefore, the dose is accumulated in very small volumes, and ultimately at the cellular level, delivered at a much higher dose rate than the average dose rate calculated for the entire exposure. This has been called the "golf ball" effect by Fowler and Van Limbergen [14]. Biological equivalent doses calculated without accounting for this effect are usually overestimating the tissue tolerance and pulsed dose rate appears "hotter" than expected [1].

In summary, whenever pulsed dose rate brachytherapy departs from its original hourly pulse without interruption at night, it becomes biologically closer to a HDRBT than a continuous LDRBT [14, 46].

There is no data available for authors indicating a reliable use of one from many radiobiological models for the purpose of comparing different brachytherapy techniques and different fractionation schema. We analyzed existing radiobiological models and chose the BED formula for calculations of biologically effective doses. Three PDRBT fractionations schemas with different length of intervals (1.2 and 4 hours, respectively) between pulses were analyzed. Original treatment plans of patients treated in Greater Poland Cancer Center were used for calculations. The results show that prolongation of intervals between pulses in PDRBT was connected with the decrease of BED values in healthy tissues, presented by chosen critical points. Critical points were chosen as the nearest points from the applicator surface. Those observations were similar before and after optimization of treatment plans. Prolonging the interval length influenced better protection of healthy tissues circumjacent treated tumor, but simultaneously prolonged treatment time (the same total dose given to the patient but in a longer time). In clinical practice it means the decrease of number of treated patients.

\section{Conclusions}

1. Prolongation of intervals between pulses in PDR brachytherapy is connected with lower values of BED doses in healthy tissues.

2. It seems that longer intervals between pulses reduce the risk of late complications, but also decreases number of cured patients.

3. Addition of optimization influenced increase of doses in healthy tissues.

\section{References}

1. The GEC ESTRO Handbook of Brachytherapy. Gerbaulet A, Potter R, Mazeron J-J, Meertens H, Van Limbergen E (eds.). ESTRO. Bruksela, 2002.

2. Mould RF, Battermann JJ, Martinez AA et al. Brachytherapy from Radium to Optimization. AX Veenendaal. Nucletron B.V. 1994.

3. Nag S. High Dose Rate Brachytherapy - a Textbook. Futura Publishing Company Inc., Armonk 1994.

4. Speiser BL, Mould RF. Brachytherapy for the $21^{\text {th }}$ Century. AX Veenendaal. Nucletron B.V. 1998.

5. Mazeron JJ, Boisserie G, Baillet F. Pulse dose rate curietherapy. Bull Cancer Radiother 1995; 82: 332-335.

6. Skowronek J. Comparison of effectiveness and risk of complications after Pulsed-Dose-Rate Brachytherapy and High-DoseRate Brachytherapy using Biologically Effective Dose model. Rep Pract Oncol Radioth 2005; 10: Suppl 1.

7. Skowronek J, Piotrowski T, Zwierzchowski G. PDR brachytherapy - describing of a method and a review of clinical applications. Rep Pract Oncol Radioth 2001; 4: 197-202.

8. Sminia P, Schneider CJ. From continuous low dose rate brachytherapy to pulsed brachytherapy. Exp Strahlenther Klin Strahlenbiol 1996; 5: 146-147.

9. Brenner DJ, Hall EJ, Huang Y et al. Potential reduced late effects for pulsed brachytherapy compared with conventional LDR. Int J Radiat Oncol Biol Phys 1995; 31: 201-210.

10. Chen CZ, Huang Y, Hall EJ et al. Pulsed brachytherapy as a substitute for continuous low dose rate: an in vitro study with human carcinoma cells. Int J Radiat Oncol Biol Phys 1997; 37: 137-143.

11. Hall EJ, Brenner DJ. Pulsed dose rate brachytherapy: can we take advantage of new technology? Int J Radiat Oncol Biol Phys 1996; 34: 511-512.

12. Brenner DJ, Hall EJ. Conditions for the equivalence of continuous to pulsed dose rate brachytherapy. Int J Radiat Oncol Biol Phys 1991; 20: 180-190.

13. Fowler JF, Mount M. Pulsed brachytherapy: the conditions for no significant loss of therapeutic ratio compared with traditional low dose rate brachytherapy. Int J Radiat Oncol Biol Phys 1992; 23: 661-669.

14. Fowler JF, Van Limbergen EF. Biological effect of pulsed dose rate brachytherapy with stepping sources if short half-times of repair are present in tissues. Int J Radiat Oncol Biol Phys 1997; 37: 877-883. 
15. Brenner DJ. Radiation biology in brachytherapy. J Surg Oncol 1997; 65: 66-70.

16. Dale RG, Jones B. The clinical radiobiology of brachytherapy. Br J Radiol 1998; 71: 465-483.

17. Millar WT, Hendry JH, Canney PA. The influence of the number of fractions and bi-exponential repair kinetics on biological equivalence in pulsed brachytherapy. Br J Radiol 1996; 69: 457-468.

18. Pop LA, Millar WT, Visser AG et al. Clinical implications of incomplete repair parameters for rat spinal cord: the feasibility of large doses per fraction in PDR and HDR brachytherapy. Int J Radiat Oncol Biol Phys 2001; 51: 215-226.

19. Brenner DJ, Hall EJ, Randers-Pehrson G et al. Quantitative comparisons of continuous and pulsed low dose rate regimens in a model late-effect system. Int J Radiat Oncol Biol Phys 1996; 34: 905-910.

20. Brenner DJ, Schiff PB, Huang Y et al. Pulsed-dose-rate brachytherapy: design of convenient (daytime-only) schedules. Int J Radiat Oncol Biol Phys 1997; 39: 809-815.

21. Visser AG, van den Aardweg GJMJ, Levendag PC. Pulsed dose rate and fractionated high dose rate brachytherapy: choice of brachytherapy schedules to replace low dose rate treatments. Int J Radiat Oncol Biol Phys 1996; 34: 497-505.

22. Steel Gordon G. Basic Clinical Radiobiology. Edward Arnold, London 1993; 72-79.

23. Barendsen GW. Dose fractionation, dose rate, and isoeffect relationship for normal tissue responses. Int J Radiat Oncol Biol Phys 1982; 8: 1981-1997.

24. de Pree C, Popowski Y, Weber D et al. Feasibility and tolerance of pulsed dose rate interstitial brachytherapy. Int J Radiat Oncol Biol Phys 1999; 43: 971-976.

25. Fowler JF. The linear-quadratic formula and progress in fractionated radiotherapy. Br J Radiol 1989; 62: 679-694.

26. Maciejewski B. Tolerancja zdrowych tkanek w radioterapii nowotworów. Odczyny popromienne. Centrum Onkologii Instytutu im. Marii Skłodowskiej-Curie, Gliwice 1991 [in Polish].

27. Dale RG. The application of the linear-quadratic dose-effect equation to fractionated and protracted radiotherapy. Br J Radiol 1985; 58: 515-528.

28. Thames HD, Hendry JH. Fractionation in Radiotherapy. Taylor and Francis, London 1987.

29. Levendag PC, Schmitz PI, Jansen PP et al. Fractionated highdose-rate and pulsed-dose-rate brachytherapy: first clinical experience in squamous cell carcinoma of the tonsillar fossa and soft palate. Int J Radiat Oncol Biol Phys 1997; 38: 497-506.

30. Peiffert D, Castelain B, Thomas L et al. Pulse dose rate brachytherapy in head and neck cancers. Feasibility study of a French cooperative group. Radiother Oncol 2001; 58: 71-75.

31. Keilholz L, Seegenschmiedt MH, Lotter M et al. Effect of dose per pulse, pulse duration and total exposure time of pulsed dose rate brachytherapy: Results of an in-vitro model. J Brachyther Int 1998; 14: 59-69.

32. Keilholz L, Seegenschmiedt MH, Lotter M et al. Effects of fractionation and dose rate in PDR brachytherapy of B14 cells. Strahlenther Onkol 1998; 174: 64-70.

33. Brenner DJ, Hall EJ, Huang Y et al. Potential reduced late effects for pulsed brachytherapy compared with conventional LDR. Int J Radiat Oncol Biol Phys 1995; 31: 201-210.

34. Fowler JF. Why shorter half-times of repair lead to greater damage in pulsed brachytherapy. Int J Radiat Oncol Biol Phys 1993; 26: 353-356.

35. Fowler JF. Are half-limes of repair reliably shorter for tumors than for late normal-tissue effects? Int J Radiat Oncol Biol Phys 1995; 31: 189-190.

36. Mason KA, Thames HD, Ochran TG et al. Comparison of continuous and pulsed low dose rato brachytherapy: biological equivalence in vivo. Int J Radiat Oncol Biol Phys 1994; 28: 667-671.

37. Armour EP, White JR, Armin A et al. Pulsed low dose rate brachytherapy in a rat model: dependence of late rectal injury on radiation pulse size. Int J Radiat Oncol Biol Phys 1997; 38: 825-834.

38. Haustermans K, Fowler J, Landuyt W et al. Is pulsed dose rate more damaging to spinal cord of rats than continuous low dose rate? Radiother Oncol 1997; 45: 39-47.

39. Pop LA, Millar WT, van den Plas M et al. Radiation tolerance of rat spinal cord to pulsed dose ratio (PDR) brachytherapy: the impact of differences in temporal dose distribution. Radiother Oncol 2000; 55: 301-310.

40. Fowler JF. Why shorter half-times of repair lead to greater damage in pulsed brachytherapy. Int J Radiat Oncol Biol Phys 1993; 26: 353-356.

41. Sminia P, Schneider ChJ, Koedooder K et al. Pulse frequency in pulsed brachytherapy based on tissue repair kinetics. Int J Radiat Oncol Biol Phys 1998; 41: 139-150.

42. Pop LA, van den Broek JF, Visser AG et al. Constraints in the use of repair half times and mathematical modeling for the clinical application of HDR and PDR treatment schedules as an alternative for LDR brachytherapy. Radiother Oncol 1996; 38: 153-162.

43. Scalliet P, Landuyt W, van der Schueren E. Kinetics of repair: its influence in low dose rate irradiations. Radiother Oncol 1988; 11: 249-251.

44. Brenner DJ, Hall EJ. Fractionated high dose rate versus low dose rate regimens for intracavitary technique of the cervix. $\mathrm{Br}$ J Radiol 1991; 64: 133-141.

45. Hall EJ, Bedford JS: Dose rate: its effect on the survival of HeLa cells irradiated with gamma rays. Radiat Res 1964; 22: 305-315.

46. Sminia P, Schneider ChJ, van Tienhoven G et al. Office hours pulsed brachytherapy boost in breast cancer. Radioth Oncol 2001; 59: 273-280. 